\title{
The Skin Barrier in Patients with Lichen Simplex Chronicus
}

\author{
Georgieva F, *Bakardzhiev I \\ Department of Dermatology and Venerology, MedicalUniversity of Varna, MedicalUniversity of Varna
}

Received: May 10, 2016; Accepted: May 20, 2016; Published: May 27, 2016

*Corresponding author: Assoc. Prof. Ilko Bakardzhiev, Medical College, Medical University of Varna, Tsar Osvo boditel 84, Bulgaria, Tel: +359 888768 413; E-Mail: varna2008@gmail.com

\begin{abstract}
Background: The main function of the skin is to protect body from environmental factors. The intact skin is a barrier to the uncontrolled water loss, proteins and plasma components from the organism. Lichen Simplex Chronicus (LSH) is a common extremely scratching disease. Prurituselicits a scratch response, initiating the itch-scratch cycle, which in turn aggravate the inflammatory response and damaged the normal epidermal barrier status.
\end{abstract}

Objective: The purpose of this study is to evaluate changes in barrier functions of skin and distinguish its role in pathogenesis of LSH. Materials and Methods: Transepidermal Water Loss (TEWL) and Hydratation $(\mathrm{H})$ of epidermis in healthy and damaged skin were measured in 56 non-hospitalized patients.

Results: The most visible pathological changes were found in patients with duration of LSH 19-24 months-TEWL mean 27.30g.m2.h and $\mathrm{H}$ mean $23.15(\mathrm{p}=0.003)$. Strong correlation between pathological levels of TEWL and $\mathrm{H}$ and severity of disease was obtained. Thus in group of patients stage II TEWL was mean $31.22 \mathrm{~g} . \mathrm{m} 2 \mathrm{~h}$, while in group stage I TEWL was mean 16.23g.m2.h. $(p=0.005)$ Similar were results from measurement of $\mathrm{H}$ : in group of patients stage III $\mathrm{H}$ was mean 20.25 , while in group stage I H was mean $28.46(\mathrm{p}=0.003)$.

Conclusion: All the reported and analyzed results indicate that disorders of skin barrier are connected with severity and duration of LSH. This is the first study in our country, which aims to measure the impact of changes in skin barrier on clinical characteristics of LSC.

Keywords: Lichen Simplex Chronicus; Skin Barrier Evaluation; TEWL; Hydratation

\section{Introduction}

Lichen Simplex Chronicus (LSH) is a common skin disorder characterized by lichenification of skin as a result of excessive scratching [1] LSH is distributed worldwide and affects adults with a mild preference for female [2]. Pathogenesis of this dermatosis is not well distinguished. Disorders of skin barrier are described as a trigger or enhance pathological symptoms of LSH [3]. There is an altered skin barrier with varying combination of allergens, irritants and skin pathogens that result in a changed immuno regulatory process [4]. This study explores the possible correlation or predomination of changes in skin barrier function and characteristic of LSH disease.

\section{Material and Methods}

\section{Settings and sample}

The study was conducted among 56 non-hospitalized patients (35 female and 21 male; mean age 49.46years; range 29-64 years) who visit dermatology unit in medical center "Medeia" between January 2013 and January 2015.Patients has the following inclusion criteria: one or more lichen plaques, highly pruritic, accumulation of normal skin lines, excoriations. Diagnosis was based on clinical observation and dates from patient's history. Socio demographic data are shown in table 1. The characteristics connected to the disease (duration and severity) are shown on

Table 1: Socio demographic data.

\begin{tabular}{|l|l|}
\hline \multicolumn{1}{|l|}{} & Patients \\
\hline Age & $\begin{array}{l}\text { mean age 49.46 years; range 29-64 } \\
\text { years }\end{array}$ \\
\hline Gender Male & $21-37.5 \%$ \\
Female & $35-62.5 \%$ \\
\hline Employment & \\
Employed & $36-64.28 \%$ \\
\hline Unemployed & $15-26.78 \%$ \\
\hline Students & $2-3.57 \%$ \\
Retiree & $3-5.35 \%$ \\
\hline Education Primary & $5-8.92 \%$ \\
Secondary & $14-25 \%$ \\
High & $37-66.07 \%$ \\
\hline
\end{tabular}

Table 2: Disease duration

\begin{tabular}{|c|c|c|}
\hline Disease duration in months & \multicolumn{2}{|c|}{$\begin{array}{c}\text { Frequency } \\
\text { (\%) }\end{array}$} \\
\hline 12 & \multicolumn{2}{|c|}{40.5} \\
\hline $13-24$ & \multicolumn{2}{|c|}{34.2} \\
$25-36$ & \multicolumn{2}{|c|}{10.0} \\
\hline $37+$ & \multicolumn{2}{|c|}{11.6} \\
\hline total & \multicolumn{2}{|c|}{3.7} \\
\hline Don't know & 56.3 \\
\hline total & 56 & 100.0 \\
\hline
\end{tabular}


Table 3: Disease severity.

\begin{tabular}{|c|c|c|}
\hline Stage of disease severity & \multirow{6}{*}{\multicolumn{2}{|c|}{$\begin{array}{c}\text { Frequency } \\
\text { (\%) } \\
0 \\
0.52 \\
21.57 \\
62.10 \\
10.52\end{array}$}} \\
\hline Stage 0 & & \\
\hline Stage I & & \\
\hline Stage II & & \\
\hline Stage III & & \\
\hline Stage IV & & \\
\hline Total & 56 & 100.0 \\
\hline
\end{tabular}

Table 4: Distribution of measuring points.

\begin{tabular}{|c|c|c|}
\hline \multicolumn{2}{|c|}{ Localization of measuring points } & \multirow{2}{*}{ Frequency } \\
\hline Damaged & Distal zone & \\
\hline Nuchal areas & $\begin{array}{l}\text { Interior surface } \\
\text { hands }\end{array}$ & of $14(25 \%)$ \\
\hline Ankles & $\begin{array}{l}\text { Interior surface } \\
\text { hands }\end{array}$ & of $11(19,65 \%)$ \\
\hline Anterior tibial & $\begin{array}{l}\text { Interior surface } \\
\text { hands }\end{array}$ & of $9(16,09 \%)$ \\
\hline $\begin{array}{l}\text { Extensor surface } \\
\text { forearms }\end{array}$ & $\begin{array}{l}\text { of Interior surface } \\
\text { hands }\end{array}$ & of $7(12,5 \%)$ \\
\hline Inner thighs & $\begin{array}{l}\text { Interior surface } \\
\text { hands }\end{array}$ & of $3(5,4 \%)$ \\
\hline Anogenital area & $\begin{array}{l}\text { Interior surface } \\
\text { hands }\end{array}$ & of $12(21,43 \%)$ \\
\hline
\end{tabular}

Table 2 and Table 3.

\section{Measures}

We used instrumental methods, including, measuring $\mathrm{H}$ and TEWL in healthy and damaged skin to evaluate the functioning of Stratum Corneum (SC). The degree of $\mathrm{H}$ was measured with a capacitance meter (Corneometer CM 825), and the TEWL was determined using a measurement instrument Tewameter ${ }^{\circledR}$ TM 300. The areas examined were closely and in distance of the pathologic lesions. The exact localization of measuring points are shown on table 4.

The severity of the disease was evaluated by EASI score. (Eczema Area and Severity Index) [5]. According to this scale patients were divided in 5 groups. Stage 0 without skin changes; Stage 1 up to $29 \%$ of skin surface is damaged, Stage 2 up to $49 \%$ of skin surface is damaged, Stage 3 up to $69 \%$ of skin surface is damaged, Stage 4 more than $69 \%$ of skin surface is damaged.

The statistical analysis was performed with SPSS v.21.0 for Windows. Hypotheses were tested using $\chi^{2}$-criteria (for the descriptive profile data). Construct validity was tested by factor analysis. Results with $\mathrm{p}<0.001$ were interpreted as statistically significant

\section{Results And Discussion}

The results obtained from measuring TEWL in healthy and damaged skin show that the levels of TEWL in healthy skin are normal $(0-15$ g.m2.h/ range from 8g.m2.h to 17.8g.m2.h.) The levels of TEWL in damaged skin were higher. The pathological changes were more visible in patients from age group 56+ - range20-32(mean27.2) and in group 46-50 years range 1938(mean 27.88).There were no significant differences in patients from different age groups. We compare the TEWL dividing patients according the duration of the disease. The pathological changes were more visible in patients with duration of LSH 19-24 months- mean 27.30g.m2.h and more than 24 months from 20g. m2.h to 32g.m2.h-mean 27g.m2.h. $(p=0.003)$. Most distinct trend for correlation was accounted comparing TEWL in pathological skin and severity of disease. In group of patients stage II TEWL was mean 31.22 g.m 2.h, while in group stage I TEWL was mean 16.23g.m2.h.( $p=0.005)$.

The results obtained from measuring $\mathrm{H}$ in healthy skin are normal (26.07/ range from 20 to 30.) The levels of $\mathrm{H}$ in damaged skin were lower (23.32/ range from 10 to 30.). The pathological changes show no differences compare to the age of participants. Also we compare the $\mathrm{H}$ dividing patients according the duration of the disease. The pathological changes were more visible in patients with duration of LSH 19-24 months- mean 23.15 and more than 24 months 18.75 ( $\mathrm{p}=0.008$ ) Most distinct trend for correlation was accounted comparing $\mathrm{H}$ in pathological skin and severity of disease. In group of patients stage III $\mathrm{H}$ was mean 20.25 , while in group stage I H was mean $28.46(\mathrm{p}=0.003)$

The results from measuring TEWL and $\mathrm{H}$ are shown in table 5 (according age), table 6 (according duration) and table 7 (according stage).

\section{Discussion}

An understanding of the structure, the integrity and function of the stratum corneum of the skin is closely connected with pathogenesis of several dermatoses [6]. Many authors point out that in dermatoses with a clinical picture of extreme dryness and scratching there are the changes in skin barrier $[7,8,9]$. Clinical picture of LSC is represented by areas with dry, itchy skin [10]. Greaves (2010) argues that the main symptom of LSC - itch- causes constant scratching, which leads to additional physical disturbance of the integrity of the surface layer of the epidermis, and to further dysfunction of the skin barrier [11]. Information about the state of the lipid matrix, and consequently to the integrity of skin barrier under various conditions gives the measurement of TEWL and H of stratum corneum [12]. Darlenski et al (2009) reported that quantitative indicators such TEWL , $\mathrm{H}$ of the stratum corneum and the $\mathrm{pH}$ of the skin surface are reliable, non-invasive techniques for monitoring the physical properties of the skin barrier invivo [13]. All this give us grounds to assess the levels of damage of the skin barrier by measuring TEWL, and $\mathrm{H}$ of stratum corneum of the skin Measurement in two zones (healthy and damaged skin) allow us to define the role of the skin barrier status in pathogenesis of LSC. All these scientific facts correlate closely with export results in our study.

Bouwstra and associates (2006) reported a correlation between clinical characteristics of skin diseases and changes in barrier function [14]. Other authors found no statistically significant relationship between disturbed homeostasis of the skin barrier and the expression of the disease symptoms [15]. The results from our study show the presence of such dependence 
Table 5: The results from measuring TEWL and $\mathrm{H}$ according age.

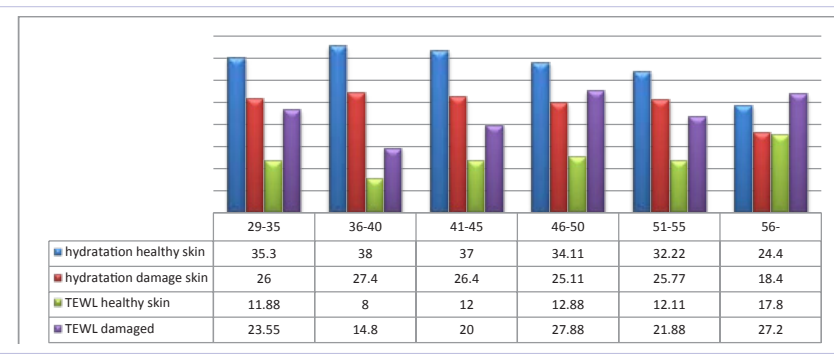

Table 6: The results from measuring TEWL and $\mathrm{H}$ according duration.

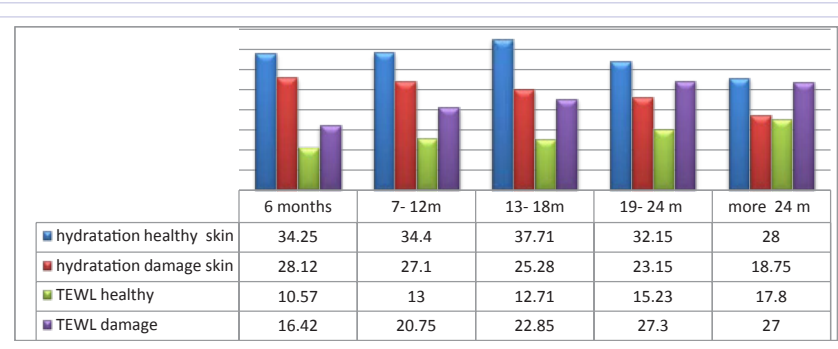

Table 7: The results from measuring TEWL and $H$ according stage.

\begin{tabular}{|c|c|c|c|}
\hline & stagel & stagell & stagellI \\
\hline whdratation healthy skin & 37.38 & 33.17 & 30.16 \\
\hline - hydratation damage skin & 28.46 & 25.88 & 20.25 \\
\hline$\square$ TEWL healthy & 9.76 & 14.9 & 16.66 \\
\hline$\varpi T E W L$ damage & 16.23 & 24.1 & 31.22 \\
\hline
\end{tabular}

in dividing patients by disease severity. Thus, in patients with moderate severity of disease mean value of TEWL was $31.22 \mathrm{~g}$ / $\mathrm{m} 2$ / $\mathrm{h}$, while those with mild severity of disease have mean value of $16.23 \mathrm{~g} / \mathrm{m} 2 / \mathrm{h}$.) ( $\mathrm{p}=0.009)$. Regarding the indicator $\mathrm{H}$ in patients with moderate disease severity $\mathrm{H}$ in pathological lesion was reported a mean of 25.88 units, while those with mild severity of disease account mean 28.46 units) ( $p=0.048$ ) At the same time dividing patients according the duration of disease showed small differences between different groups. As the most significant TEWL near pathological lesion was reported in patients with disease duration of 19-24 months mean value of $27.30 \mathrm{~g} / \mathrm{m} 2 / \mathrm{h}$ and those with duration longer than 24 months - .mean value of ' $20 / \mathrm{m} 2 / \mathrm{h}$ to $32 \mathrm{~g} / \mathrm{m} 2 / \mathrm{h}(\mathrm{P}=0.003)$ Low levels of $\mathrm{H}$ in the area to pathological lesions were measured in patients with disease duration of 19-24 months- (median 23.15 units ) and those lasting longer than 24 months from - 15 units to 22 units. (mean18. 75 units) ( $\mathrm{p}=0.001)$.

6 In 1985 Werner and associates published data for increase TEWL in healthy and pathological skin in a study of patients with atopic dermatitis. As a result, the authors presume primary defect in the epidermal barrier [16] Our results showed that from all included in the study patients only $30.95 \%$ had pathology in skin barrier(increased TEWL and decreased $\mathrm{H}$ ) in measuring of healthy skin stretch. Disturbed pathological function of skin barrier (increased TEWL and reduced H) in measuring of damaged skin was reported in $85.71 \%$. These results questioned the existence of a primary defect in the epidermal barrier and its leading role in unlocking LSC. The correlation between the degree of damage of the skin barrier and severity of the disease give reason to assume that itch aggravate the disease and leads to the dysfunction of barrier homeostasis.

\section{Conclusion}

The absence of correlation between changes in hydration and TEWL and some of the characteristics connected to the disease means that in patients suffering from LSH there are different independent pathological ways of development of illness. Disorders of skin barrier could be described as a trigger only of pruritoceptive pruritusin LSC. This study does not include monitoring of patients before and after treatment but the results suggest that the inclusion of local therapy which improves the quality of skin barrier would have a good therapeutic effect.

\section{References}

1. Lotti T, Buggiani G, Prignano F. Prurigo nodularis and lichen simplex chronicus. Dermatologic Therapy. 2008;21:42-46. doi:10.1111/ j.1529-8019.2008.00168.x.

2. Martin-Braufau R, Corbalan-Berna J, Ramirez-Andrero A, BraufauRedondo C, Limlnana-Gras R. Personality differences between patients with lichen simplex chronicus and normal population:A study of pruritus. Eur J Dermatol. 2010;20(3):359-363. doi:10.1684/ ejd.2010.0961.

3. Yosipovitch G, Samuel LS. Neuropathic and psychogenic itch. Dermatol Ther. 2008;21(1):32-41. doi:10.1111/j.1529-8019.2008.00167.x.

4. Proksch E, Fölster-Holst R, Jensen JM. Skin barrier function, epidermal proliferation and differentiation in eczema. Journal of dermatological science. 2006;43(3):159-169.

5. Serup J, Gregor BE, Jemec, Gary L Grove. Handbook of non-invasive methods and the skin. $2^{\text {nd }}$ ed. CRC press, 2006.

6. Scluplein RJ, Blank IH. Permiability and the skin. Physiol Reviews. 1971:51(4):702-747

7. Fitzpatricks Dermatology in General Medicine $6^{\text {th }}$ edition: 2002:1:1164-1209

8. Madison KC, Swartzendruber DC, Wertz PW, Downing DT. Presence of intact intercellular lipid lamellae in the upper layers of the stratum corneum. J Invest Dermatol. 2007;88(6):714-718.

9. Williams ML. Lipids in normal and pathological desquamation. In: Elias PM, ed. Skin Lipids, Vol. 24, New York, NY: Academic Press. 2011:211-262.

10. James, Berger, Elston. Andrews' Diseases of the Skin. Saunders Elsevier. 10th ed. 2006.

11. Greaves MW. Pathogenesis and treatment of pruritus. Curr Allergy Asthma Rep. 2010;10(4):236-242. doi:10.1007/s11882-010-0117-z.

12.Seidenari S, Framcomano M, Mantovani L. Baseline Biophysical parameters in subjects with sensitive skin Contact Dermatitis. 2008;38(6):311-315.

13. Darlenski R, Sassing S, Tsankov N, Fluhr JW. Non-invasive in vivo 
methods for investigation of the skin barrier physical properties Eur J Pharm Biopharm. 2009;72(2):295-303. doi:10.1016/j. ejpb.2008.11.013.

14. Bouwstra JA, Ponec M. The skin barrier in healthy and disease state BiochimBiophys Acta. 2006;1758(12):2080-2095.
15. Grubauer G, Elias PM, Feingold KR. Transepidermal water loss; the signal for recovery of barrier structure and function. J Lipid Res. 1989;30(3):323-333.

16. Werner Y, Lindberg M. Transepidermal water loss in dry and clinically normal skin in patients with atopic dermatit. ActaDermVenereol. 1985;65(2):102-105. 